\title{
Synthesis and Property of Nanostructured ZnS
}

\author{
Xiaosheng Fang, ${ }^{\circ}$ Yoshio Bando, and Dmitri Golberg \\ International Center for Materials Nanoarchitectonics(MANA), National Institute for \\ Materials Science (NIMS), Namiki 1-1, Tsukuba, Ibaraki 305-0044, Japan \\ E-mail: BANDO.Yoshio@nims.go.jp
}

Nanostructured Materials are a new class of materials, having dimensions in the 1 to 100 $\mathrm{nm}$ range, which provide one of the greatest potentials for improving performance and extended capabilities of products in a number of industrial sectors. Zinc sulfide ( $\mathrm{ZnS})$, is one of the first semiconductors discovered and one of the most important materials in the electronics with a wide range of applications, including LEDs, electroluminescence, flat panel displays, infrared windows, sensors, lasers, and biology etc. The research on nanostructured $\mathrm{ZnS}$ have recently stimulated great interest due to their potential value for understanding fundamental physical concepts and for applications in constructing nanoscale electric and optoelectronic devices [1].

In this paper, the novel synthesis, property and potential application of nanostructured $\mathrm{ZnS}$ achieved in our group will be presented. Firstly, immaculately controlled growth of $\mathrm{ZnS}$ nanostructures in various sizes and shapes, including the first fabrication of hexagonal faceted $\mathrm{ZnS}$ single-crystal nanotubes, hierarchical $\mathrm{ZnS}$ multipod structures composed of $\mathrm{ZnS}$ nanowire arrays, nanostructured $\mathrm{ZnS}$ used as template for the fabrication of other nanotubes, novel various metal-ZnS heterostructures, Ga-doped $\mathrm{ZnS}$ nanowire-precursors for $\mathrm{ZnO} / \mathrm{ZnGa}_{2} \mathrm{O}_{4}$ nanotubes and micrometer long quantum confined $\mathrm{ZnS}$ nanobelts etc, will be introduced briefly [2]. And then we will discuss our results on intrinsic properties of nanostructured $\mathrm{ZnS}$, such as their optical property which was investigated by optical spectroscopy and high spatially resoled cathodoluminescence spectroscopy. For example, a new ultraviolet emission peak $(\sim 355 \mathrm{~nm})$ was discovered within $\mathrm{ZnS} / \mathrm{ZnO}$ biaxial nanobelt heterostructures (Fig .1) [3]. The electrical properties of single $\mathrm{ZnS}$ structures are also observed under in-situ TEM-STM. Finally, the potential applications by using the above-synthesized nanostructured $\mathrm{ZnS}$ will be presented. Such as, individual and multiple single-crystalline $\mathrm{ZnS}$ nanobelts with sharp ultraviolet (UV) emission at room temperature have been assembled as 'visible-blind' UV Sensors, especially in the UV-A region. The photoresponsivity of $\mathrm{ZnS}$ nanobelt-based UV sensors exhibited over three orders of magnitude gain under the UV light illumination as compared to a visible light (Fig .2) [4].

\section{References}

[1] X. S. Fang, Y. Bando et al. J. Mater. Sci. Technol. 24 (2008) 512; J. Mater. Sci. Technol. 24 (2008) 520.

[2] X. S. Fang, Y. Bando et al. Adv. Mater. 19 (2007) 2593.

[3] J. Yan, X. S. Fang, Y. Bando et al. Nano. Lett. 8 (2008) 2794.

[4] X. S. Fang, Y. Bando et al. Adv. Mater. adma.200802441, 2009, in press

[5] This work was supported by the MANA, MEXT, tenable at NIMS, Japan. The aid of

Drs. U. K. Gautam, G. Z. Shen, L. W. Yin, J. Q. Hu, P. Costa and others, NIMS is gratefully acknowledged. 

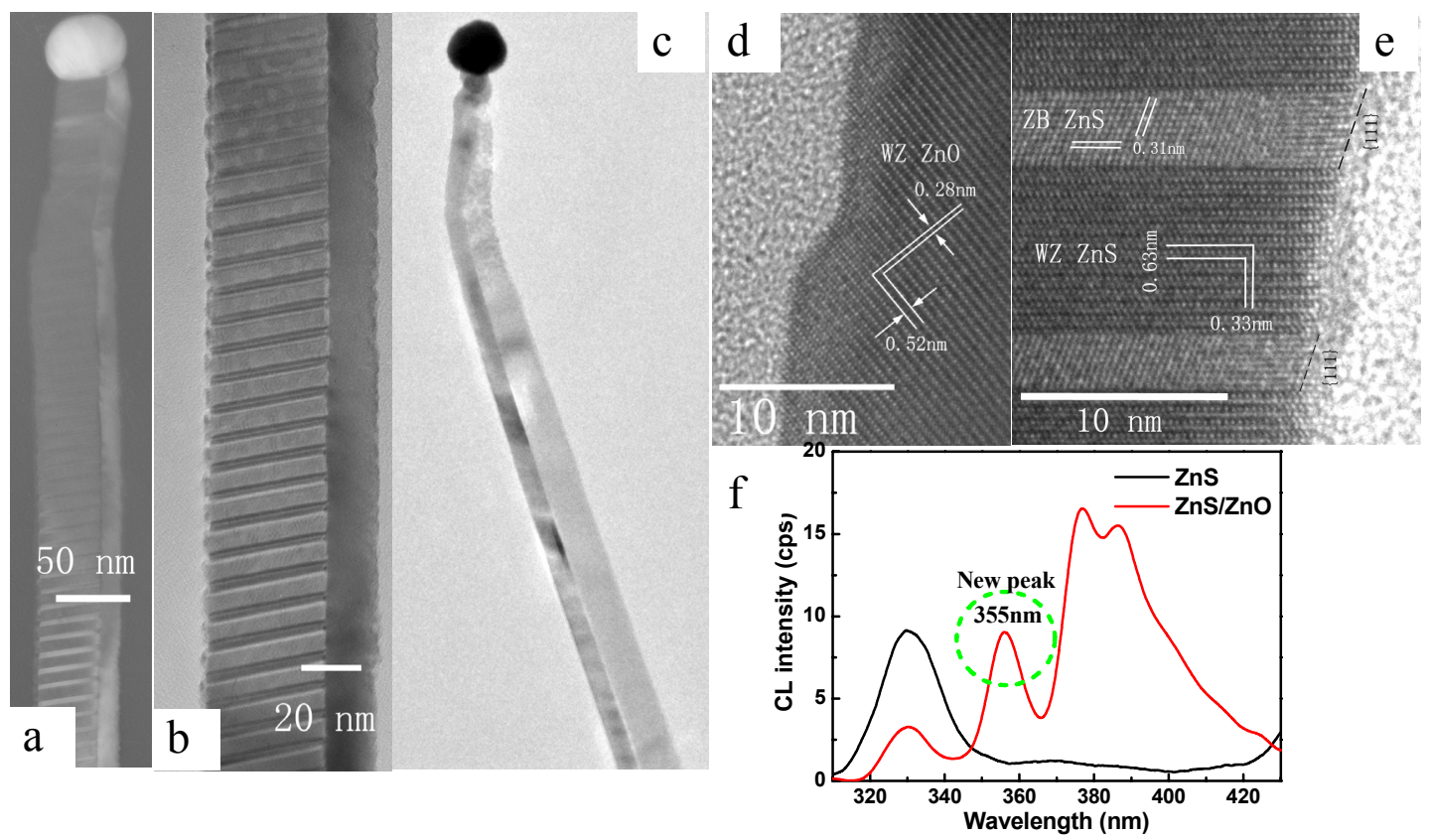

Fig. 1. The unique structure and cathodoluminescence of $\mathrm{ZnS} / \mathrm{ZnO}$ biaxial nanobelt heterostructures[3]. (a)-(c). Typical TEM images of two novel $\mathrm{ZnS} / \mathrm{ZnO}$ biaxial nanobelt heterostructures, (d) and (e). HRTEM images recorded from both sides of heterocrystalline $\mathrm{ZnS} /$ single-crystalline- $\mathrm{ZnO}$ biaxial nanobelts. (f). Representative CL spectra obtained at $\sim 30 \mathrm{~K}$ from individual $\mathrm{ZnS} / \mathrm{ZnO}$ biaxial nanobelts and pure $\mathrm{ZnS}$ nanobelts. A new ultraviolet emission peak $(\sim 355 \mathrm{~nm})$ is observed for individual $\mathrm{ZnS} / \mathrm{ZnO}$ biaxial nanobelts which is absent either in the pure $1 \mathrm{D} \mathrm{ZnS}$ or $\mathrm{ZnO}$ nanostructures.
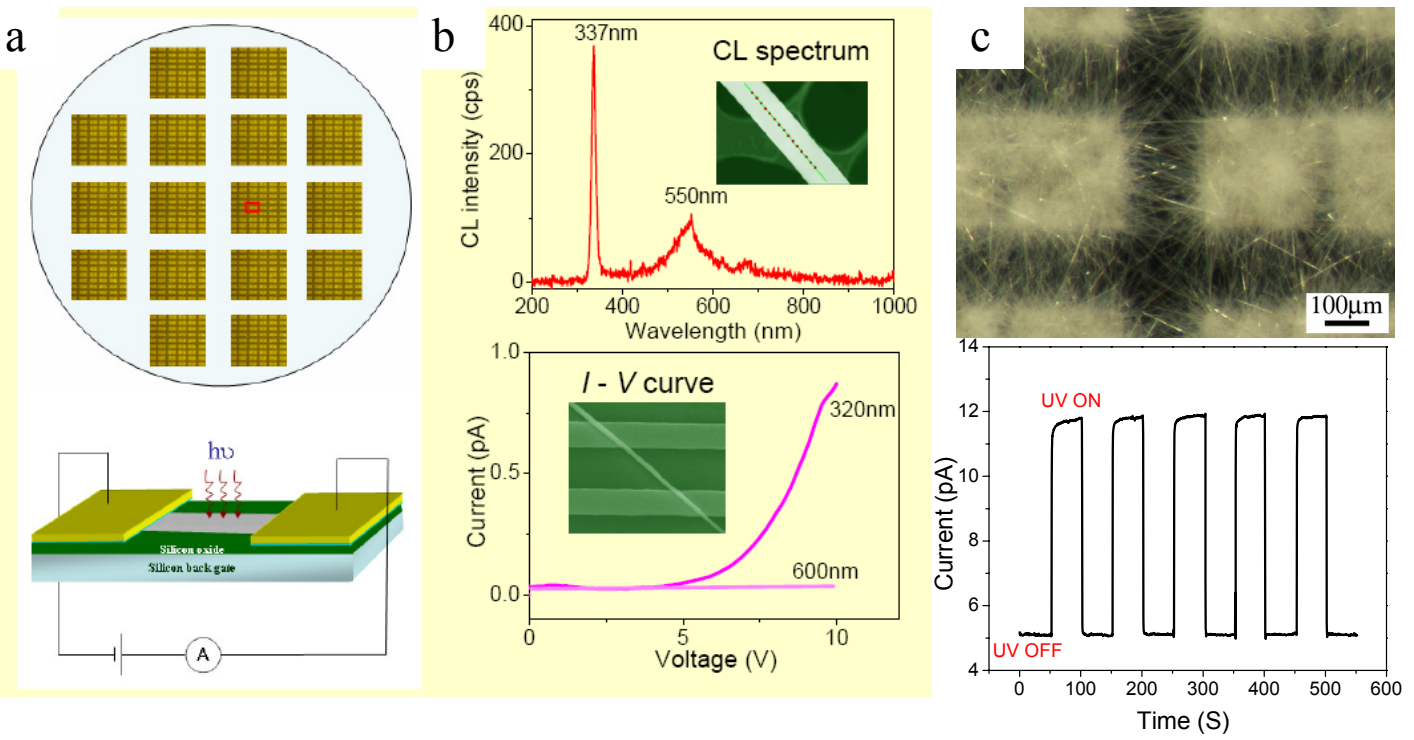

Fig. 2. Individual and multiple single-crystalline $\mathrm{ZnS}$ nanobelts with sharp ultraviolet (UV) emission ( $337 \mathrm{~nm})$ at room temperature have been assembled as UV Sensors[4]. The high spectral selectivity combined with high photosensitivity and fast time response justify the effective utilization of the present $\mathrm{ZnS}$ nanobelts as "visible-blind" UV photodetectors in different areas. 